Revista de la red interuniversitaria de estudios sobre las literaturas rioplatenses contemporáneas en Francia

$20 \mid 2019$

Situación

\title{
Acerca del alma de los animales
}

A propos de l'âme des animaux

About the soul of animals

\section{Rafael Arce}

\section{OpenEdition}

Journals

Electronic version

URL: http://journals.openedition.org/lirico/8273

DOI: $10.4000 /$ lirico.8273

ISSN: 2262-8339

\section{Publisher}

Réseau interuniversitaire d'étude des littératures contemporaines du Río de la Plata

\section{Electronic reference}

Rafael Arce, «Acerca del alma de los animales », Cuadernos LIRICO [En línea], 20 | 2019, Publicado el 10 julio 2019, consultado el 02 junio 2020. URL : http://journals.openedition.org/lirico/8273 ; DOI : https://doi.org/10.4000/lirico.8273

This text was automatically generated on 2 June 2020

\section{(c) (i) (9)}

Cuadernos LIRICO está distribuido bajo una Licencia Creative Commons Atribución-NoComercialSinDerivar 4.0 Internacional. 


\title{
Acerca del alma de los animales
}

\author{
A propos de l'âme des animaux \\ About the soul of animals
}

Rafael Arce

\section{Dos concepciones del espectro animal}

1 Informe sobre ectoplasma animal (2014) de Roque Larraquy y Diego Ontivero es, de modo simultáneo, un dispositivo contemporáneo y actual. Es contemporáneo tanto por su año de publicación como por la relativa juventud de sus autores. También lo es por combinar escritura e imágenes visuales. Pero es además actual porque inscribe en su factura problemáticas que están en la agenda de la filosofía, la crítica y la política de nuestro tiempo: la crisis del humanismo, la animalidad, las nociones de vida y de muerte. Por añadidura, Informe se inscribe en la tradición de la literatura argentina en un doble movimiento: reapropiándose del "imaginario de lo paranormal tal como se consolidó en las décadas del veinte y del treinta" (Quereilhac 2014) y situándose como un epígono tardío de la borgiana imaginación razonada.

2 Esta actualidad ha hecho de Informe un objeto de lectura rápidamente interpretable. En efecto, semejante dispositivo parece destinado a alimentar la bibliografía crítica en la que predomina el enfoque biopolítico. Una primera reticencia, entonces, la provoca esta situación: ¿qué pertinencia puede tener una lectura como la hecha desde las problemáticas actuales cuando el objeto mismo parece haberlas ya procesado? Las lecturas críticas han tendido a extraer de Informe esbozos teóricos provisorios o fragmentarios, pero siempre homogéneos. Inversamente, se ha subrayado la hibridez genérica del dispositivo (De Mauro Rucovsky 2015: 124-125). O, por el contrario, se ha conjeturado que se trata de un libro de prosas breves, cuyas ilustraciones se yuxtaponen sin una conexión clara (Quereilhac 2014). Sin embargo, no se ha prestado atención a lo que Informe tiene de más singular: el carácter lacunar del relato y la heterogeneidad irreductible de los pensamientos que insinúa. 
Informe es una novela de ciencia ficción cuyo verosímil trabaja una serie de registros de los que se reapropia. Las imágenes de Ontivero se incorporan a la ficción y nada autoriza a considerarlas como yuxtapuestas al texto. La novela utiliza el procedimiento del manuscrito encontrado, que el título indica de entrada. El género "informe" imprime a la prosa su particular estilo: las imágenes, como soporte visual, contribuyen al verosímil, pues un informe científico o técnico sobre espectros animales debería estar acompañado de las llamadas ectografías. Los otros géneros primarios, como la carta, el cuaderno personal o el instructivo final, se incorporan a este mecanismo de verosimilitud: lo hallado no sería exactamente un manuscrito, sino una carpeta incompleta en la que informes fragmentarios se han mezclado con una serie aleatoria de cartas y notas. En este sentido, el procedimiento es borgiano: la novela está compuesta de lecturas de textos y de descripciones de imágenes (las ectografias que constituyen el archivo de la Colección Solpe), algunos yuxtapuestos, varios recortados y de los cuales se otorga un resumen o solo la lacónica indicación de un presumible resumen $^{1}$. Este montaje deja numerosas lagunas e importantes saltos temporales.

De modo paradójico, es esta unidad de la novela lo que permite volver sensible su estructura lacunar, mientras que la hipótesis de una hibridación, incluso de un artefacto verbal-visual, al incorporar el montaje como un procedimiento del dispositivo (y no de la ficción novelesca), no interroga esas elipsis que vuelven posible una historia que abarca más de cuatro décadas en apenas ochenta y dos páginas, de las cuales veintidós son de imágenes. Tampoco se ha prestado atención al humor y a la ironía. Por un lado, el estilo científico sufre discretas interpolaciones disonantes, a menudo ironizadas como abusos metafóricos en la necesidad de fijar un vocabulario específico (el llamado Nomenclador de la Sociedad Ectográfica). Por el otro, las situaciones cómicas operan como interrupciones en la presunta gravedad o seriedad de lo que se narra.

5 El carácter lacunar y fragmentario del relato vuelve imposible o impertinente una versión homogénea de la espectrografía animal. El enigma de esta disciplina y sus interrogantes filosóficos es uno de los muchos que plantea la novela. Ahora bien, el primer enigma atañe a la historia misma. ¿Qué es lo que cuenta Informe? ¿Es la historia de la Sociedad Ectográfica Argentina, creada en 1911 y aquejada de una crisis en 1930 en medio de su pretensión de convertir su práctica en una ciencia? ¿Es la historia de sus dos principales ectografistas? ¿Qué sucede entre la fundación de la Sociedad llevada adelante por el enigmático Severo Solpe y los casos registrados décadas después por sus dos discípulos? ¿Trabajan Julio Heiss y Martín Rubens en el contexto de una ciencia establecida? ¿O más bien la ectografía es una mera rama de la fotografía y las teorizaciones solamente un saber técnico? ¿Qué pasó con la Sociedad después de la desaparición de su sede y la muerte de su fundador? Estas vacilaciones son estructurales: resumir la historia antes de emprender la lectura tendría como consecuencia soslayarlas.

6 La primera de las cuatro partes consiste en informes sobre captura de espectros animales realizadas entre 1938 y 1957. El orden de los informes no es cronológico, pero tampoco parece azaroso. El primero es "Federico. Buenos Aires, 1949". Se trata del registro del espectro de un perro que murió en el umbral de su casa. El encargado del caso es Julio Heiss, "promotor de la ectografía materista" (9). Su oponente, Martín Rubens, se menciona en el tercer informe: el caso es el espectro de un pato que parece causar glaucoma en el cocinero que lo horneó. Rubens es "promotor de la ectografía 
animista" (13). Esta oposición entre dos concepciones de la ectografía no será nunca desarrollada, sino cada vez sugerida. No obstante, es una discusión que merece ser interrogada. Heiss considera que el espectro es "materia tenue residual, sin sobrevida" (9). Por el contrario, la concepción de Rubens presupone una supervivencia después de la muerte. ¿Qué implica esta discusión? Se trata, en principio, de un problema que atañe al animal vivo.

7 La cuestión que plantea la polémica de los ectografistas es si el animal tiene o no alma y, de tenerla, cuál sería su naturaleza. La respuesta no es sencilla. Para el pensamiento occidental, el animal ha ido perdiendo el alma. Aristóteles fue el primero en interesarse sistemáticamente por los animales. Para el Estagirita, el alma nombra el principio vital, identificado físicamente con la respiración y metafísicamente con la capacidad de autoafección del organismo (Cragnolini 2015: 319). El alma, en consecuencia, implica la unidad del cuerpo, no pudiendo separarse en su concepto lo material de lo inmaterial. Es el pensamiento cristiano quien platoniza el alma convirtiéndola en espíritu, es decir, en una entidad inmaterial propia del viviente humano: el alma, entonces, pierde densidad, sustento material, volatilizándose (Cragnolini 2015: 320). La modernidad se funda en la célebre expulsión cartesiana: el animal es en esta concepción un autómata o una máquina, sin alma (Derrida 2008: 94).

8 Veremos que el problema del alma animal implica la definición misma de lo humano. Considerándolo en la oposición de los ectografistas, no parece azaroso que los primeros dos informes que presentan las divergencias de perspectivas examinen los espectros de un perro y de un pato. Federico, "perro querido de la familia" (9), es una mascota, es decir, el tipo de animal al que se le presupone un alma: es la sensibilidad, el afecto, lo que hace del perro una cuasi-persona, lo que por otra parte se expresa en su nombre propio. La ectografía materista confronta entonces con el animal que más lejos estaría de su concepción. Simétricamente, la ectografía animista debe vérselas con lo más alejado de la suya: la vida animal borrada en el plato de comida. Heiss reduce el espectro de Federico a su hábito: el gusto por la carne. Rubens subjetiviza lo más posible al pato. Escribe el ectografista, no sin humor: "Para macerarse en rencor, necesita una memoria, y para vindicarla requiere un futuro, o una idea de futuro" (13, cursiva nuestra).

Las posiciones materista y animista traducen concepciones de la vida animal que en nuestra época conviven de manera tácita, en una suerte de economía anímica: se trata de una cierta cantidad de alma, yendo de lo menos animado (el viviente no humano convertido en alimento) a lo más (la mascota). En el medio de los dos informes, sin referencia a ningún ectografista en particular, se presenta el caso del mono albino en Montevideo. El mono es el viviente que patentiza la animalidad del hombre o, también, las presuntas cualidades humanas de un animal superior: "Se obtienen seis segundos en giroscopio en los que el mono camina erguido como un ser humano" (11). Es decir, este caso es la inquietud de la cercanía, y de la distancia, del Homo Sapiens respecto del resto de los vivientes.

Los dos últimos casos de la primera parte refuerzan la oposición. La aparición de peces espectrales en un edificio es interpretada de modo diverso: para Rubens, se trata de un cardumen, mientras que para Heiss es "el eco espectral de un océano completo" (26). En el último caso, Rubens va más lejos: Saki, un gato castrado, se vuelve ocioso y "aprende a pensar" (29). Durante su vida, prefiere estar echado al lado de su dueño, mientras una gata en celo lo convoca desde el jardín. Muerto, permanece en un árbol, indiferente a la 
gata, que se siente atraída por su brillo fosforescente. Lo que pretende este informe es explicar una anomalía, dado que hasta entonces los casos revelaban que la aparición del espectro se situaba exactamente en el lugar de su hábito. Si el de Saki era permanecer dentro de la casa, ¿por qué su espectro titila sobre un árbol del jardín? La extravagante conjetura de Rubens resuelve la incógnita a partir de su posición teórica: "Quiere sentir el frío de estar muerto al aire libre" (29). De modo que Saki vive su muerte. El animismo de Rubens implica la existencia del alma animal como supervivencia más allá de su desaparición física.

\section{Biopolítica y alegoría}

11 Las dos concepciones del espectro animal parecen haberse bifurcado de la temprana teoría que esboza el descubridor de la ectografía. El capítulo III narra el descubrimiento accidental de la técnica fotográfica ectoplasmática o ectografía. En un cuaderno personal del año 1914, Solpe anota: "Llamamos espectro a un tipo de residuo matérico inscripto en el éter que el animal deja de sí cuando muere" (49). Las especificaciones de este residuo corresponden solo al hábito del animal y a la síntesis de sus características corporales. Pero en una entrada del diario correspondiente a solo tres días después afirma: "La inscripción en éter de un animal muerto como espectro, mensurable por su claridad en watts, resulta de los hábitos que el animal supo reiterar en vida y del sufrimiento físico intenso" (51). Tal como lo señala Heiss, la inscripción del ectoplasma de Federico es posible por la persistencia tanto del hábito alimenticio de la carne como de la costumbre de echarse en el umbral de la casa. En el caso del pato de Rubens, no puede ser otro que el sufrimiento la causa de la inscripción: el espectro aparece con el cuello quebrado, aunque de la acción del cocinero solo se diga que lo persiguió y lo horneó. De modo que el espectro aparece o bien en el espacio de frecuentación del animal vivo o bien en el lugar en el que sufrió una muerte violenta. El caso de una cobra muerta a balazos en la parte II agrega elementos de polémica entre las dos versiones de la ectografía:

Rubens cree que las percibe [a las balas] y que muere con ellas cada vez, y que la ansiedad y el dolor de la cobra al morir inscribieron en su espectro el gesto constante de la huida.

Heiss sugiere que las balas perforaron este y otros sectores del éter en torno al cuerpo, provocando filtraciones similares a una cobra que huye (41).

Heiss parece ir más lejos que Solpe y negarle al animal la posibilidad misma de sufrimiento. En efecto, ese dolor físico intenso, del que habla Solpe, contribuye al espesor del alma animal, a su subjetivación. El sufrimiento es precisamente el aspecto soslayado en la extensa polémica filosófica en torno al límite entre lo humano y lo animal:

Pensando en la fuente y en los fines de esta compasión, alguien como Bentham, es bien sabido, propuso hace dos siglos cambiar la forma misma de la cuestión animal, tal como domina el discurso de la tradición tanto en su argumentación filosófica más refinada como en el lenguaje corriente del sentido común. La cuestión, decía Bentham poco más o menos, no es saber si el animal puede pensar, razonar, hablar, etc. [...] La cuestión, previa y decisiva será saber si los animales pueden sufrir. Can they suffer? (Derrida 2008: 43-44) 
Plantear la pregunta por el sufrimiento, alterando el modo de interrogación en torno a la cuestión animal, saca la discusión del ámbito de la razón, la comunicación y el lenguaje, y la coloca en el terreno de la ética y, a fortiori, de la política. La atribución, o extirpación, del alma, resulta clave en relación con este problema. Nadie negaría hoy el dolor de una mascota, y sin embargo la impersonalidad (es decir, la extirpación del alma) de un sinnúmero de animales sacrificados (por cuestiones alimenticias, de experimentación científica, de desastres ecológicos, etc.) es denegatoria de ese mismo sufrimiento que se asume ante el animal subjetivizado (Cragnolini 2015: 326-327).

La historia de la Sociedad Ectográfica y los casos que documentaron los dos discípulos de Solpe transcurren durante el auge de los regímenes totalitarios en Argentina. La cuarta parte, que cuenta las peripecias de Solpe en medio de la crisis de su institución, se sitúa en los días previos y posteriores al golpe de Estado que derrocó al gobierno de Hipólito Yrigoyen el 6 de septiembre de 1930. Además, dos casos de la primera parte aluden a la autodenominada Revolución Libertadora que en 1955 derrocó el gobierno de Juan Domingo Perón. Uno es el ya mencionado caso del cardumen:

El horizonte de la pampa es plano porque imita la superficie del mar que lo cubrió durante millones de años. Al irse, el mar dejó un tendal de muerte marina que sirve de alimento a los animales de tierra. Cuando llegan los hombres, no construyen casas de piedra, porque creen que el mar volverá tarde o temprano. Estos hombres son borrados por otros que hacen la ciudad. Crece el entusiasmo vertical. El edificio Alas (ex Atlas, Agrupación de Trabajadores Latinoamericanos Sindicalizados S.A.), a cargo de la Secretaría de Aeronáutica, se inaugura en 1957 como el más alto de Buenos Aires (25).

17 La historia geológica de la pampa pretende explicar el caso del cardumen espectral. Ahora bien, la asepsia de su estilo informativo disimula otra historia: la de la violencia constitutiva de la civilización. Aunque el pasaje se refiera a lo arquitectónico, "la ciudad" tiene algo de alegórico: no es una ciudad concreta, sino el concepto mismo de ciudad, es decir, el espacio político. Por otra parte, ese "entusiasmo vertical" no es solo arquitectónico: ¿cuáles son esos hombres que "borran" a los otros hombres? ¿No es la ciudad, es decir, la civilización, lo que ha permitido definir lo específicamente humano? La verticalidad estaría indicando la erección del Homo Sapiens que borra su pertenencia a la naturaleza, su parte animal. Esta alegoría del origen de la humanidad, en la que un gigantesco matadero transforma al mamífero terrestre bípedo en Homo Sapiens, se vuelve historia de una nación particular en la que esos ecos espectrales continúan asediando: también hay un borrado en la transformación del sindicato en una dependencia del gobierno militar (literalmente, el borrado de la " $\mathrm{t}$ " en el nombre Atlas). El entusiasmo vertical en el que consiste el proceso de hominización continúa en la erección del Estado autoritario.

La otra alusión a la autodenominada Revolución Libertadora es alegórica. Es el quinto informe de la primera parte. El caso está datado el 16 de septiembre de 1955 en el "Palacio del Pollo al Minuto", sobre la calle Corrientes de Buenos Aires. Una cuchara queda suspendida como por arte de magia sobre un omelette y, frente al plato, la comensal no puede mover su cabeza, a la que siente sujetada por el ojo. La ectografía muestra un pollo en gestación en el glóbulo ocular y un ectoplasma rodeando la cuchara, descrito por Rubens como "un jirón informe de vapor etérico" (18). El ojo se da por perdido, se espera la gestación, se registra la ruptura del cascarón y nacimiento del pollo. 
19 Es difícil sustraerse a la interpretación alegórica, porque el texto la tienta deliberadamente: fecha y lugar exacto del golpe de Estado, algo que se está gestando y que pronto hará irrupción. Aun así, este sentido alegórico es inestable, ya que parece socavado por la ironía: en el Palacio (espacio del poder soberano) del Pollo al Minuto, el momento clave de la historia argentina se figura en la detención del reloj-cucú. Cuando Rubens teme que el pollo espectral nazca del ojo, lo mozos bromean con que "cante la hora" (18). Asimismo, por cuanto Informe transcurre entre las décadas del diez y del cincuenta, las imágenes del ojo inmóvil y la gestación podrían aludir también a El huevo de la serpiente de Ingmar Bergman (1977). Recordemos que la historia se sitúa en Berlín en la década del veinte y que la imagen que ilustra la emergencia del nazismo se refiere al carácter visible-invisible (como el espectro) del huevo de la serpiente: su membrana transparente deja ver un reptil pequeño, casi una lagartija, entre pueril y simpática, que disimula la forma monstruosa que adoptará la criatura nacida. El reemplazo de la serpiente por el pollo tiene un efecto humorístico, incluso al lector argentino puede recordarle la expresión coloquial listo el pollo, para aludir a una situación ya consumada (en este caso, nada menos que el derrocamiento de un gobierno democrático).

20 No obstante, la interpretación alegórica deja un resto. El omelette, al pudrirse mientras se espera al ectografista, deja ver el pico de un pollo en estado de gestación. Su espectro no es el residuo matérico de un animal que murió, sino la manifestación de lo que todavía no es y permaneció suspendido en ese advenimiento. De modo que el espectro rebasa el concepto de fantasma como supervivencia del alma o persistencia matérica más allá de la muerte física del organismo y abarca lo todavía-no-nacido. El animal nunca murió porque para poder hacerlo debería primero haber vivido. El espectro no es entonces solo la persistencia de algo pasado, sino también la potencia de algo por venir.

Los momentos alegóricos son inestables. Sucede que no podemos reducir lo político a lo alegórico, es decir, a los acontecimientos históricos a los que se alude de manera a la vez elíptica y nítida. Coincidimos con la lectura biopolítica en considerar lo político como un pensamiento: el espectro animal plantea inmediatamente un problema de esta índole, dice algo sobre la historia de la sociedad argentina, aunque rebase esa coyuntura. No obstante, este pensamiento no es algo que se enuncie como una teoría, sino que es más bien un inasible que el texto demanda formular conjeturalmente más allá de la trama de pensamientos y lecturas que lo articulan.

\section{Tanatopolítica y espectralidad}

22 La cuarta parte narra las peripecias de la Sociedad Ectográfica cuando se activa el protocolo de espectración, que significa la creación de espectros artificiales: los animales son amarrados en mallas metálicas y mueren por la sed y por los efectos adversos de la inmovilidad. Para que no inquieten a los empleados con sus gritos, se les extirpan las cuerdas vocales. Se puede leer una correspondencia entre el sometimiento violento de estas vidas animales y la administración biopolítica de los cuerposciudadanos propia del capitalismo tardío (De Los Ríos 2018: 226). Ahora bien, esa correspondencia hace de la situación de los animales una metáfora de la política humana. Pero ¿por qué la fábrica de muerte en la que se convierte la Sociedad Ectográfica tendría similitudes con la administración política de la vida humana? Según la distinción de Foucault, mientras la soberanía antigua se caracterizaba por la prerrogativa del derecho soberano a hacer morir o dejar vivir, el biopoder moderno se 
caracteriza por hacer vivir o dejar morir. Mientras la soberanía se ha pensado como prerrogativa de dar muerte, la biopolítica se define por su acción de administrar, aumentar, multiplicar pero a la vez controlar y regular las poblaciones (Foucault 2008: 128-130). No obstante, esta novedad del biopoder afecta principalmente al viviente humano, mientras que el animal seguiría estando sujeto al régimen antiguo o, dicho de otro modo, el animal siempre se habría encontrado en situación biopolítica (Cragnolini 2016: 225). Porque la biopolítica consiste en hacer vivir la vida humana digna y dejar morir la vida humana indigna y la vida animal no tiene cabida en este esquema, en la medida en que no se considera propiamente vida, sino que se convierte en objeto de disponibilidad, desaparece como bien del capital, dejando solo su espectro. Considerar el martirio que los animales sufren durante el protocolo espectral como una metáfora de la administración biopolítica es escamotear el sufrimiento y la muerte literales de toda vida no humana: es soslayar el mecanismo tanatológico real, material, que debe invisibilizarse para que la administración biopolítica funcione.

Por otro lado, mientras que en las partes primera y segunda las alegorías operan como alusiones a lo histórico-político, en la cuarta parte la trama misma de la historia de la Sociedad Ectográfica es indiscernible de la trama política. Lo lacunar y alusivo de la novela parece tematizar la espectralidad: hiatos y elipsis poseen una densidad por la cual lo que no se narra posee la misma fuerza que lo narrado. El procedimiento de montaje (que también es isomorfo con el problema de la fotografía y el cine como medios técnicos de captura) vuelve experimentable lo no narrado como espectro del relato.

La presunta complicidad entre ciencia y aparato represivo del Estado es quizás una interpretación demasiado apresurada (De Mauro Rucovsky 2015: 128). Dijimos que no es posible afirmar de modo tajante si la ectografía se trata de una pseudo ciencia o de una mera técnica, "una rama específica de la fotografía" (Cortes Rocca 2016: 1). ¿Es Severo Solpe, con el guiño de su nombre propio, un personaje siniestro que es financiado por la derecha argentina y que pone finalmente su ectografía al servicio del fascismo? ¿O es un obseso de la disciplina, que solo piensa en salvar su institución de la ruina y cuyas maniobras tienen un fin pragmático? El texto suspende toda respuesta taxativa a estas preguntas en la tensión irresoluble entre lo narrado y lo elíptico, en el modo en el que lo alegórico parece desmentir lo literal, y lo irónico y lo humorístico poner en duda lo alegórico.

Si, por un lado, puede interpretarse, como se ha hecho, una complicidad entre la maniobras de Solpe y la emergencia de la derecha, lo que lleva la lectura en la dirección de una figuración de los mecanismos de la biopolítica (Cortes Rocca 2016: 2), por el otro, puede considerarse la Sociedad Ectográfica misma como pieza del entramado institucional de la maquinaria fascista. Cuando Solpe le cuenta al senador conservador Dubarry las penurias de la institución, en cartas de las cuales solo podemos acceder a ciertos fragmentos, lamenta que sus empleados se estén "amotinando" (64) porque reprueban el protocolo de espectración. En este contexto de rebelión, aparecen un par de zapatos clavados frente a la puerta de su despacho. Este extraño signo se reitera en el final, aunque esta vez aparecen clavados en el marco exterior de la ventana del despacho: "Los zapatos no son una amenaza, ni parecen un mensaje cifrado. No tienen humor, ni violencia, ni un sentido alegórico inmediato" (62). La descripción parece una ironía o una denegación: humor, violencia, sentido alegórico, son elementos constitutivos de Informe. Los zapatos podrían ser de un hombre invisible, un fantasma 
humano, alguien que se mueve en las sombras. Podrían ser los zapatos de Bartolomé Descalzo, militar y político argentino que fue pieza clave en el complot cívico-militar que terminó en el golpe de Estado que encabezó Félix Uriburu.

Por otro lado, la crisis financiera de la Sociedad se debe al alza en el precio del cesio, el metal utilizado para ectografiar: "A fines de la década del treinta, el valor del cesio, que se usa en las válvulas termoiónicas, se ha disparado por el aumento en las ventas de receptores de radio" (62). ¿A qué alude este aumento en las ventas? Desde luego, a las circunstancias del creciente complot y al papel que tuvo la propaganda en la legitimación del golpe de Estado. Sin embargo, Solpe escribe: "Nunca hubiera pensado, senador, que la ficción de las radionovelas y los programas de variedades musicales me pondrían en jaque de este modo" (62). Hacia el final de la novela, se dirá que Solpe contempla las manifestaciones de apoyo al golpe y el arribo de columnas del ejército como un "desfile". Es como si no percibiera lo que está sucediendo en el país y más bien actuara como si hubiera contraído el llamado "cuadro o síndrome del cesio": la observación cotidiana de lo muerto quita a los ectografistas tanto el miedo primario a la noche y sus misterios cuanto la empatía por el sufrimiento del prójimo.

Dijimos al comienzo que Informe era a la vez actual y contemporáneo. Más allá del año de publicación, al pie de la página final se consigna un lugar y una fecha: Buenos Aires, enero de 2014. Este anclaje es significativo, porque el dato se consigna al interior del texto y reitera el procedimiento que titula cada "informe". En efecto, en varios tramos el lector puede tener la sospecha de que ese narrador vagamente plural podría estar leyendo el Informe desde el presente ${ }^{3}$. A pesar de su actualidad, la novela no tiene nada que ver con esas "escrituras del presente" que parecen caracterizar cierto estado de la narrativa argentina más contemporánea ${ }^{4}$. Al trabajar en un registro borgiano y al interrogar la historia argentina de la primera mitad del siglo XX, es más bien anacrónico. La ironía, el manejo de los temas actuales, y la fecha al pie de la página final, podrían estar señalando una distancia, una conciencia acerca del problema de la vida como el más candente de la teoría política. Entonces, escapando a lo actual como lo que pretende ceñir el presente, lo intempestivo de Informe estaría en esta interrogación por la muerte en un momento en el que predomina el paradigma vitalista de la resistencia y la consideración de la soberanía como la del omnipresente biopoder: "al mismo tiempo que la biopolítica parece ser una de las formas ineludibles del pensamiento actual, la tanatopolítica nombra las formas más devastadoras del siglo pasado" (Biset 2012: 246). La perspectiva de Informe es la de un siglo XX ya pasado en el que la tanatopolítica hizo posible la biopolítica.

Una pregunta que ninguna lectura ha planteado es por qué no hay espectros humanos en la novela y, sin embargo, este parece ser el mayor enigma. La disputa por el alma implica la distinción del hombre como animal superior, en la medida en que lo propiamente humano ha debido establecerse a condición de extirpar algo al resto de los vivientes. Si retomamos la distinción entre alma y espíritu, podemos decir que la hominización es un proceso de espiritualización, intrínsecamente idealista. Contra la certidumbre post-humanista, algunos pensadores consideran que el proceso de hominización no ha concluido y que, en consecuencia, es apresurado hablar de un fin del humanismo (Ludueña Romandini 2010: 214). Los totalitarismos, fenómeno político específico del siglo XX, fueron la continuación de ese proceso abierto. Derrida recuerda las palabras de Theodor Adorno al respecto: "Los animales serían los judíos de los idealistas, los cuales no serían sino fascistas virtuales. El fascismo empieza cuando se 
insulta a un animal, incluso al animal en el hombre" (Derrida 2004: 37). La Sociedad Ectográfica como máquina de muerte, como tanatopolítica, funciona con el mismo mecanismo que el moderno matadero $\mathrm{y}$, más aún, con el mismo mecanismo que el campo de exterminio. En este punto se situaría la relación que Informe sugiere entre auge del totalitarismo y sometimiento de los animales: la tanatopolítica trabaja como un mecanismo impersonal, aséptico, administrativo, de aniquilación, puesto al servicio del biopoder como contracara de su administración de la vida. Si la erección espiritual del sujeto humano se ha realizado a expensas de la vida animal, su forma actual consistiría en la superproducción industrial de tortura y de muerte, y su naturalización en la forma de la administración burocrática y la impersonalidad tecno-científica. No hay animal en tanto que tal: la interrogación de su estatuto ha estado siempre al servicio de la definición de lo humano.

Los espectros son el resto inasimilable, el retorno de lo oprimido-reprimido, la persistencia de lo que se supone extirpado, aniquilado, sajado: no solo la animalidad del hombre en tanto que fondo bajo-corporal, sino lo expulsado de la humanidad como vida no digna. Pero también son lo que adviene, lo que todavía no es presente, lo virtual y lo posible. La idea misma de espectro animal parece la contra-cara simétrica de la de vida humana: como si lo espectral convocara necesariamente lo animal y viceversa.

\section{El espectro de las masas}

En cuanto al desenlace de la novela, Gabriel Giorgi, también desde la biopolítica, lee una continuidad entre espectros, animales y emergencia de las masas como factor político en la historia argentina. Incluso habla de "pueblo" (2016). La interpretación nos parece errónea: las multitudes que dificultan el arribo de Solpe a la institución el día del golpe constituyen la sociedad civil que celebra y festeja el derrocamiento de Irigoyen. Claramente, no son la masa-pueblo, sino la masa fascista: "Desde afuera entran volantes y pétalos de flores que la gente suelta desde los balcones a los cadetes de la escuela militar" (77). En el segundo capítulo de la cuarta parte, "Rituales colectivos", Solpe cuenta al senador la vida mundana junto a su mujer. La frivolidad y el sentido del humor disimulan esa indolencia que caracteriza al síndrome del cesio:

Participar de rituales colectivos produce una envidiable sensación de realidad y de pertenencia al mundo. Puedo verlo en la mansedumbre de Leticia cuando vuelve de misa o cuando comenta la noticia de un linchamiento que considera justo (69).

La reprobación moral que Leticia comparte con los empleados, que consideran el sufrimiento de los animales durante el protocolo como "un acto de crueldad" (64), no parece contradecirse con la aprobación del linchamiento "justo". Hay sufrimientos que son crueles y otros que son justos: aquellos que el dispositivo sacrificial de nuestras modernas sociedades deniegan y que impiden ver el mecanismo tanatológico que hace avanzar a las poblaciones humanas. El dispositivo técnico de captura del ectoplasma vuelve visible lo invisibilizado. El ritual colectivo, aunque parezca un modo retórico en la pluma de Solpe, es el de la multitud fascista. Mientras que la emergencia de las masas populares es otro de los hiatos de la historia: ¿qué pasó entre el 6 de septiembre de 1930 y el 16 de septiembre de 1955? Dice Cortes Rocca:

En la Argentina de los años cuarenta, cuando no hay palabras para nombrar lo que acecha, lo que irrumpe, lo que toma los espacios públicos en una nueva reconfiguración de lo político, la lengua se plaga de animales. El aluvión zoológico es una invasión animal en el suelo de la lengua... (2016) 

"mapa moral de consignas criteriosas, instrucciones para la educación de sus nietos y sugerencias de vestuario" (81). El fragmento es la descripción de un castigo correctivo de la conducta infantil: "Entre las formas de la penitencia recomiendo la que consiste en colocar al niño en un rincón de la sala mirando hacia la pared" (81). Desde luego, hay una correspondencia entre lo que acaba de producirse en el país y el instructivo. Habría que pensar también si en nuestras modernidades tardías no es apresurado hablar de una biopolítica en la primera mitad del siglo XX y considerar más bien la perduración de la llamada por Foucault "sociedad disciplinar". Las masas requieren un liderazgo que castigue y discipline, así como el niño necesita la guía paternal rígida. Pero el niño se sitúa también entre el sujeto humano y el animal: para convertirse en hombre, debe ser educado, socializado, sometido.

\section{BIBLIOGRAPHY}

Biset Emmanuel, “Tanatopolítica”, Nombres N² 26, Córdoba, 2012, p. 245-274.

Contreras Sandra, "En torno a las lecturas del presente", En torno al realismo y otros ensayos, Rosario, Nube Negra, 2018, p. 77-98.

Cortes Rocca Paola, “Ciencia espectral. Literatura, fotografía y otros dispositivos”, Estudios Curatoriales $\mathrm{N}^{\circ} 4$, Buenos Aires, 2016, s/n.

Cragnolini Mónica (2015), “"Animula, vagula, blandula", o sobre el alma perdida de los animales”, Lo Sguardo - rivista di filosofia $\mathrm{N}^{\circ} 18$, p. 317-329.

--- (2016), “El animal como "capital" en la biopolítica: ambiente y biodiversidad", Extraños animales. Filosofía y animalidad en el pensar contemporáneo, Buenos Aires, Prometeo.

De Los Ríos Valeria, “Ciencia, animal y fantasma en La comemadre e Informe sobre ectoplasma animal de Roque Larraquy", Estudios Filológicos N 61, 2018, p. 215-227.

De Mauro Rucovsky Martín, “Informe sobre ectoplasma humano. Biopolítica y ficción”, Babedec $\mathrm{N}^{\circ} 5$ (9), Rosario, 2015, p. 118-145.

Derrida Jacques (2004), Acabados, Madrid, Trotta.

--- (2008), El animal que luego estoy si(gui)endo, Madrid, Trotta.

Foucault Michel, Historia de la sexualidad 1. La voluntad de saber, Buenos Aires, Siglo XXI, 2008.

Giorgi Gabriel, “El animal, el espectro”, La Fuga N 17, Web. Consultado el 1/02/19.

Roque y Ontivero Diego, Informe sobre ectoplasma animal, Buenos Aires, Eterna Cadencia, 2014.

Ludueña Romandini Fabián, La comunidad de los espectros I. Antropotecnia, Buenos Aires, Miño \& Dávila, 2010.

Cuadernos LIRICO, 20 | 2019 
Quereilhac Soledad, “Invención fantasmagórica”, La Nación, 11 de septiembre de 2014, Web.

Consultado $1 / 02 / 19$.

\section{NOTES}

1. Paola Cortes Rocca vincula la novela con La invención de Morel: "Sin embargo, Informe sobre ectoplasma animal es algo así como el reverso exacto de La invención. Allí el fantasma es prueba de la persistencia de lo humano, indestructible pese a que el cuerpo perezca. Aquí, la ectografía animal redefine lo viviente en términos que minan la tradición humanista que el fantasma -incluido en esa tradición hasta el momentoviene a confirmar: el alma, la razón, la identidad" (2016: 2). Preferimos desentrañar la prosapia borgiana del texto, aunque, desde luego, si se considera que La invención de Morel posee también una filiación borgiana, esta relación no es ajena a nuestra lectura.

2. La mañana del golpe, Solpe y su mujer han pasado la noche en vela mirando ectografías: "No entienden del todo las noticias de la radio, pero sí que parte de la acción pasa por la Avenida de Mayo y Solpe teme una nueva intrusión en el edificio" (77).

3. La indicación espacio-temporal final puede estar revelando ese presente desde el que se lee el Informe que tan difícil es de situar: "Los mayores defectos de Solpe, que recordamos con cariño, eran la grandilocuencia y el entusiasmo" (55). ¿Quiénes son los que recuerdan a Solpe? ¿No será la Sociedad Ectográfica Argentina una sociedad secreta que sigue operando aún hoy? De nuevo, la viabilidad de esta conjetura le da a la ficción un barniz borgiano. Es posible que, como lo señala Cortes Rocca, la ficción se sitúe en un tiempo contemporáneo al inicio de la novela, es decir, los años cincuenta. Sin embargo, ¿no puede ponerse en duda esta conjetura haciendo funcionar juntos esa inscripción del texto en nuestra contemporaneidad por el fechado final y su ironía y su humor?

4. Nos referimos a esa inclinación de una buena parte de la narrativa argentina contemporánea por situar sus ficciones en los tiempos actuales (Contreras 2018: 77-98).

\section{ABSTRACTS}

This work proposes a reading of Informe sobre ectoplasma animal (2014) by Roque Larraquy and Diego Ontivero. For this, it discusses with the biopolitical readings that consider the animal specters as an image or metaphor of modern human society. By contrast, he affirms the need for a reading that interrogates the problems of animality and spectrality as ethical questions and, therefore, immediately political. This involves distinguishing the notions of soul and spirit, which imply the construction of man as a process of spiritualization.

Este trabajo propone una lectura de Informe sobre ectoplasma animal (2014) de Roque Larraquy y Diego Ontivero. Para ello, discute con las lecturas biopolíticas que consideran los espectros animales como imagen o metáfora de la moderna sociedad humana. En contraste, señala la 
necesidad de una lectura que interrogue los problemas de la animalidad y la espectralidad como cuestiones éticas y, por lo tanto, inmediatamente políticas. Esto implica distinguir las nociones de alma y de espíritu, que implican la construcción del hombre como un proceso de espiritualización.

Ce travail propose une lecture de Informe sobre ectoplasma animal (2014) de Roque Larraquy et Diego Ontivero. Pour cela, il met en discussion les lectures biopolitiques qui considèrent les spectres animaux comme une image ou une métaphore de la société humaine moderne. En revanche, il souligne la nécessité d'une lecture qui interroge les problèmes de l'animalité et de la spectralité en tant que questions éthiques et donc immédiatement politiques. Cela implique de distinguer les notions d'âme et d'esprit que supposent la construction de l'homme en tant que processus de spiritualisation.

\section{INDEX}

Palabras claves: Animalidad, espectralidad, totalitarismos, alegoría, tanatopolítica

Keywords: Animality, spectrality, totalitarianism, allegory, tanatopolitic

Mots-clés: Animalité, spectralité, totalitarismes, allégorie, tanatopolitique

\section{AUTHOR}

RAFAEL ARCE

IHUCSO-UNL-CONICET

rafael.arce@gmail.com 